\title{
QUALIDADE SOCIAL DA EDUCAÇÃO PÚBLICA: ALGUMAS APROXIMAÇŌES
}

\author{
Maria Abádia da SiLVA*
}

RESUMO: Este artigo busca compreender a educação como uma prática social e um ato político. Em razão da complexidade e do caráter polissêmico do conceito de qualidade, analisa como esse termo, utilizado para fins econômicos, passou a servir também como conceito de qualidade da educação pública. Em seguida, apresenta as aproximações e dimensóes sinalizadoras da qualidade social da educação escolar com a intenção de, pela experiência docente e práticas pedagógicas, sinalizar alternativas referenciais para uma educação escolar de qualidade social.

Palavras-chave: Políticas educacionais. Qualidade social. Gestão democrática. Formação de professores. Educação básica pública.

\section{SOCIAL QUALITY OF PUBLIC EDUCATION: SOME APPROACHES}

ABSTRACT: This paper strives to understand education as a social practice and political act. Due to the complexity and polysemous character of the concept of quality, it analyzes how this term, used for economic ends, has also begun to be used as a concept for public education. It then presents the approaches and signalizing dimensions of the social quality of school education in order to, through teaching experience and pedagogical practices, point out alternative references for a school education with social quality.

Key words: Educational policies. Social quality. Democratic management. Public basic education.

Doutora em Educação e professora adjunta da Faculdade de Educação da Universidade de Brasília (UNB).E-mail: abadia@unb.br 


\section{Introdução}

\section{A} questão - o que é qualidade social da educação pública? - tem instigado a reflexão daqueles que compreendem a educação como uma prática social e um ato político. Em razão da complexidade e do caráter polissêmico do conceito de qualidade, propomo-nos a apontar alguns elementos para reflexão daqueles que trabalham com os cursos de licenciatura e de formação continuada de professores. Para delimitar o âmbito desse conceito movediço, elegemos a educação escolar como prioridade e o faremos inserindo-a no processo de soerguimento da sociedade brasileira, no sentido de se superar o distanciamento entre as classes sociais decorrente dos ordenamentos patrimonialistas enraizados nas práticas políticas.

Para tanto, o tema será analisado em duas partes: a primeira trata do conceito de qualidade no campo econômico, transposto para o conceito de qualidade da educação, e o segundo, das aproximações e dimensões sinalizadoras da qualidade social da educação escolar. A intenção é, com base na experiência docente e práticas pedagógicas, sinalizar alternativas referenciais de uma educação escolar de qualidade social.

Do conceito de qualidade no campo econômico para a qualidade da educação

As questôes sociais estão imbricadas no modo de produção e distribuição dos bens materiais produzidos pelos sujeitos na sociedade, em espaços e tempos históricos. Elas constituem parte de um todo e as separamos com a finalidade de apreender o social-histórico construído e determinado pelo movimento econômico. Os movimentos constitutivos da vida econômica e política produzem práticas e relações sociais e, ao fazê-lo, evidenciam características que a acumulação de capital assume em um tempo histórico específico (Vieira, 1992). Assim, ao constituir-se um todo, uma unidade, o econômico e o social imbricam-se, e são distinguidos para delimitar a apreciação a ser realizada com uma parte desse todo.

Então, como somos sujeitos constituídos no social e produtores desse social, a natureza humana desenvolve a capacidade de atribuir 
valores, significados, e emitir juízos a objetos, artefatos, coisas e símbolos. Socialmente, somos seres dotados da capacidade de estabelecer relações com os outros, de nos comunicarmos e de fazer opções. Ao fazer as escolhas, avaliamos, acionamos valores, visões de mundo, de sociedade e de educação, além de critérios que maximizam ou minimizam os benefícios individuais e coletivos.

Todavia, a vida na sociedade capitalista, ao tornar-se mais complexa, gerou outras necessidades que impulsionaram as práticas comerciais, evoluindo das feiras locais para compras realizadas pela internet, ao mesmo tempo em que cresce consideravelmente o número de consumidores e compradores. No mercado real ou virtual, fabricantes e comerciantes constroem desejos e criam expectativas, com o propósito de atrair consumidores, seja por necessidade, eficiência, utilidade ou praticidade do objeto, seja pela inculcação construída por meio de técnicas midiáticas e artifícios de propaganda do objeto ou da coisa a ser adquirida.

Do ponto de vista econômico, desde a infância somos inseridos nas práticas comerciais e fazemos opções. Não se trata de analisar como fazemos escolhas. No entanto, um dos elementos que acionamos é a qualidade da coisa a ser adquirida. É neste momento, então, que elegemos os elementos que expressam qualidade, segundo valores e visões de mundo. Assim, relacionar-se no mundo-mercado exige compreender e decodificar os códigos dos atos de comprar, vender, permutar e revender objetos. Trata-se de fazer escolhas, competir!

Nesse sentido, o negociante ou comerciante, por meio dos códigos comerciais, oferece um produto, um artefato, uma coisa aos consumidores e evidencia as qualidades e atributos do objeto em apreço, com a finalidade de sobrepor-se aos concorrentes e assegurar constantes negócios na praça, feira ou mercado. Um dos aspectos da relação direta entre produtores e comerciantes com os consumidores é a capacidade de se avaliar o objeto ou a coisa, acionando os atributos de utilidade, qualidade e comparabilidade. Com efeito, no campo econômico, as relações são mediadas por alguns parâmetros de qualidade que regulam compra, venda e troca, enfim, o valor monetário do objeto ou produto. Alguns deles são:

a) o bem-estar pessoal ou coletivo, conforto do objeto ou da coisa;

b) a utilidade e a praticidade que indicam a possibilidade de melhorar as condiçóes de vida; 
c) a eficácia e a economia de tempo ou um melhor aproveitamento do tempo pessoal;

d) a marca do produto que expressa status social e o seu reconhecimento pelos consumidores.

Nesse cenário comercial, poderíamos alongar muito mais a lista. No entanto, o objetivo é demonstrar que, no campo econômico, o conceito de qualidade dispõe de parâmetros de utilidade, praticidade e comparabilidade, utilizando medidas e níveis mensuráveis, padrões, rankings, testes comparativos, hierarquização e estandardização próprias do âmbito mercantil. De acordo com essa perspectiva, a qualidade de um produto, objeto, artefato ou coisa pode ser aferida com o uso de tabelas, gráficos, opiniōes, medidas e regras previamente estabelecidas. Portanto, apreender a qualidade significa aferir padrões ou modelos exigidos, conforto individual e coletivo, praticidade e utilidade que apontem melhoria de vida do consumidor. O conceito de qualidade construído na relação entre negociantes e consumidores modifica-se de acordo com as circunstâncias econômicas e sociais. Na relação mercantil, o produto, o objeto, o artefato, o símbolo, a coisa une os interesses de ambos e, ao mesmo tempo, os distingue de outros produtos pelas suas características. A qualidade é negociada, dinâmica, transitória e contém as marcas históricas da opinião pública, o que estimula o ato comparativo.

Nas políticas sociais do país, ocorre uma transposição direta do conceito de qualidade própria dos negócios comerciais para o campo dos direitos sociais e, nestes, a educação pública. A participação ativa e constante de técnicos dos organismos financeiros internacionais e nacionais na definição de políticas sociais, especialmente a educação, objeto deste estudo, demonstra a adoção do conceito de qualidade, do âmbito da produção econômica, em questôes da educação e da escola, em um processo de descaracterização da educação pública como um direito social (Souza \& Oliveira, 2003).

Nos anos de 1990, acelerou-se a transposição de medidas, níveis e índices próprios das relações mercantis para quantificar e aferir a quantidade e qualidade dos conteúdos disciplinares de séries/anos escolares materializada no Sistema Nacional de Avaliação da Educação Básica (SAEB), criado para mensurar o desempenho dos alunos do ensino fundamental ( $3^{\mathrm{a}}$ e $4^{\mathrm{a}}$ séries) e médio ( $3^{\mathrm{a}}$ série), por meio de testes 
aplicados em âmbito nacional. Qual a intenção implícita desse sistema? Introduzir os princípios de qualidade e competitividade entre escolas? Alterar o currículo escolar, ajustando-o aos conteúdos a serem cobrados nos testes de aferição de desempenho? Hierarquizar as escolas e punir aqueles que fracassam por não terem alcançado os níveis e índices aceitáveis?

A avaliação quantitativista constituiu um dos instrumentos para adaptar o sistema educacional brasileiro à nova ordem global instituída nos anos de 1990. Fonseca e Oliveira (2005) mostram que foram implementadas mudanças de cunho gerencial, voltadas para a modernização do aparato burocrático, cujo objetivo central era imprimir eficiência ao desempenho do Estado. Integravam-se ao movimento conhecido como Reforma do Estado, sob a orientação de Bresser Pereira, à frente do Ministério da Administração e Reforma do Estado (MARE), no primeiro mandato do governo Fernando Henrique Cardoso (1995-1998). Entre as ações prioritárias, destacam-se (i) a descentralização administrativa, pela qual foram transferidas funções da burocracia central para estados e municípios e para as denominadas organizações sociais, que se configuram como entidades "de direito privado públicas, não-estatais"; e (ii) a avaliação classificatória de desempenho serve ao Estado descentralizado, como forma de permitir a sua regulação. Portanto, descentralizar e avaliar tornaram-se eixos estruturantes na educação.

É preciso levar em conta que, às questôes que envolvem domínio de conhecimentos, códigos, linguagens e raciocínio lógico, próprios da natureza da formação escolar, somam-se outras, como vida familiar, ambiência cultural, condições de transporte, de alimentação, acessibilidade a livros diversos, hábitos de leitura, acesso a equipamentos tecnológicos, que, juntos, constituem a amplitude da formação. Por opção política, esses últimos elementos não são considerados nos critérios de avaliação.

Em consonância com o projeto neoliberal vigente, os organismos multilaterais trataram, inicialmente, de promover novas formas de controle da produção do trabalho escolar, por meio de mecanismos de avaliação, de currículo, de formação, de financiamento e de gestão dos sistemas de ensino e das escolas. Além disso, explicitaram claramente o papel da educação no tocante à geração de capital social 
para o desenvolvimento do capitalismo, uma vez que a educação poderia contribuir para a minimização da exclusão, da segregação e da marginalização social das populações pobres. Isto não se deve a uma questão de igualdade de direitos, mas a uma razão também econômica. Tais processos são considerados fatores impeditivos para o pleno desenvolvimento do capitalismo e podem gerar ameaças à estabilidade econômica e à ordem social dos países ricos. Nessa perspectiva, a educação visa a contribuir com a composição da força de trabalho, com a formação de consumidores e com a preservação da ordem social (Fonseca \& Oliveira, 2005).

Essa lógica gerencialista, ao preconizar a qualidade econômica, segundo a qual, para garantir desenvolvimento econômico e social, basta a intervenção do livre mercado, ou melhor, uma sociedade global livre regida pelas regras e sinais de mercado, evidencia duas situaçóes dentro da escola (Souza \& Oliveira, 2003). Uma inibe os esforços da instituição para definir coletivamente o seu projeto político-pedagógico, pois é conhecida a luta histórica em defesa do direito da escola de construir seu projeto, de fazer suas escolhas, num movimento em que todos se educam. Outra fortalece os instrumentos de controle, de fiscalização e de pressão externa nas decisões da escola. Pouco importa os saberes, se a escola como um todo desenvolve valores humanos, se caminha para o entendimento da qualidade no sentido social, se desenvolve projeto com aqueles que têm limitações. O que conta são os números e não a forma ou o processo de como os números foram gerados.

Articulados com a noção de administração racional, o Banco Mundial e parte dos técnicos da equipe brasileira imprimem uma visão também mercadológica, econômica, na estrutura dos sistemas de educação, com o objetivo de legitimar critérios de qualidade e produtividade, bem como a forma de medi-los sob a frágil aparência de eficácia.

Desse modo, programas como: Melhoria da Qualidade da Educação Básica em Minas Gerais (1995); Qualidade do Ensino Público no Paraná (1995); fundescola (1998) e Programa de Expansão e Melhoria do Ensino Médio (1998) expressam uma modalidade de qualidade a ser implementada na estrutura do sistema de educação com impactos na gestão, no currículo e na avaliação em todo o país. $\mathrm{Na}$ proposta de governo de Fernando Henrique Cardoso - "Mãos à obra Brasil" - afirma-se: 
A prioridade fundamental da política educacional consistirá em incentivar a universalização do acesso ao primeiro grau e melhorar a qualidade do atendimento escolar, de forma a garantir que as crianças tenham efetivamente a oportunidade de, pelo menos, completar as oito séries do ensino obrigatório (...). No segundo grau, a política do governo consiste em auxiliar e estimular os estados no sentido de ampliar o número de escolas, melhorar a qualidade do ensino e oferecer oportunidades de formação profissional. (Cardoso, 1994, p. 114)

A partir de 1996, esse entendimento prescrito pelo Banco Mundial, em sua proposta de reforma educativa, reporta-se ao conceito de qualidade formulado por economistas e atrelado à concepção de qualidade própria dos negócios do mercado. No documento intitulado Prioridades y estrategia para la educación, o Banco afirma:

(...) la calidad de la educación es difícil de definir y de medir. En una definición satisfactoria deben incluir los resultados obtenidos por los alumnos (...). Los resultados de la educación se pueden mejorar mediante la adopción de cuatro importantes medidas: a) el establecimiento de normas sobre los resultados de la educación; b) la prestación de apoyo a los insumos que, según se sabe, mejoran el rendimiento; c) la adopción de estrategias flexibles para la adquisición y la utilización de los insumos, d) la vigilancia de los resultados. (1996, p. 51)

Ainda na concepção dos técnicos do Banco Mundial:

(...) una vez determinados los objetivos de aprendizaje, entra en juego la tecnología del aprendizaje y requiere cinco tipos de insumos: la capacidad y motivación del alumno para aprender, la materia que se ha de aprender, un maestro que conoce la asignatura y es capaz de enseñarla, tiempo para el aprendizaje y las herramientas necesarias para la enseñanza y el aprendizaje. (Idem, p. 81).

A concepção de qualidade educacional que emana do Banco fundamenta-se na adoção de "insumos", que deverão conduzir a resultados a serem avaliados por meio de índices de desempenho e de rendimento escolar dos alunos e das escolas. Seus técnicos preconizam um raciocínio linear, segundo o qual a mera adoção de equipamentos gera resultados satisfatórios. A concepção de qualidade assentada na racionalidade técnica e nos critérios econômicos serviu e serve de referência para a formulação de políticas para a educação pública no país. Assim, 
a atualização da teoria do capital humano pelos técnicos e arautos do Banco Mundial tornou-se, para alguns governos e gestores, o norte que orienta as políticas para a educação básica e superior assentadas no conceito de qualidade advindo das bases de teorias econômicas.

\section{Aproximações e dimensões sinalizadoras da qualidade social da educação}

Ao priorizar os critérios econômicos para atribuir qualidade à educação, os governos e gestores desconsideram os limites e as imperfeições geradas pelo mercado e sua incapacidade para corrigir questôes sociais, que costumam se agravar quando deixadas à mercê dos interesses do capital financeiro e de empresários. A qualidade social na educação não se restringe a fórmulas matemáticas, tampouco a resultados estabelecidos a priori e a medidas lineares descontextualizadas.

Um olhar crítico direcionado para a trajetória da sociedade brasileira revela a distância entre as classes sociais, em decorrência de concepções políticas e medidas econômicas de privilégio para poucos e um processo de alargamento constante de exclusão social para a maioria. Foram séculos de omissão e de ocultamento das demandas da sociedade, sendo suas manifestações muitas vezes tratadas como caso de polícia e de desordem pública. No Brasil, ainda que estas manifestações ocorressem desde o tempo das províncias, o desejo dos trabalhadores por uma educação de qualidade foi atendido por meio de escolas precárias e insuficientes para a magnitude e a expectativa da demanda.

Todavia, da condição de súditos da monarquia, passamos para a de cidadãos republicanos, sem termos vivido a aprendizagem da cidadania. A República moldou os graves problemas sociais não resolvidos - entre eles, a educação pública - segundo a estrutura econômica do país, que já exigia outro tipo de trabalhador urbano. São exemplos as inúmeras tentativas de reformas educacionais que buscavam melhorar o funcionamento e a organicidade do sistema, por meio, inclusive, de financiamento mais adequado.

Nas propostas educacionais de católicos e liberais e, em seguida, nos embates entre privatistas e publicistas, estava subjacente o binômio quantidade-qualidade, que tem sido pendular na formulação das políticas para a educação básica. Em meio às disputas políticas e interesses econômicos, evidenciava-se a necessidade de educação escolar para a 
formação social de homens e mulheres e para os trabalhadores expropriados dos bens materiais e culturais (Potyara, 2008).

Passamos, agora, a mostrar como alguns fatores - internos e externos à escola - se refletem na qualidade da educação escolar. Nosso objetivo é apresentar alguns elementos indicadores de qualidade social na educação.

Dentre os determinantes externos que contribuem para a referência da qualidade da educação escolar, citamos:

a) Fatores socioeconômicos, como condições de moradia; situação de trabalho ou de desemprego dos responsáveis pelo estudante; renda familiar; trabalho de crianças e de adolescentes; distância dos locais de moradia e de estudo.

b) Fatores socioculturais, como escolaridade da família; tempo dedicado pela família à formação cultural dos filhos; hábitos de leitura em casa; viagens, recursos tecnológicos em casa; espaços sociais frequentados pela família; formas de lazer e de aproveitamento do tempo livre; expectativas dos familiares em relação aos estudos e ao futuro das crianças e dos jovens.

c) Financiamento público adequado, com recursos previstos e executados; decisões coletivas referentes aos recursos da escola; conduta ética no uso dos recursos e transparência financeira e administrativa.

d) Compromisso dos gestores centrais com a boa formação dos docentes e funcionários da educação, propiciando o seu ingresso por concurso público, a sua formação continuada e a valorização da carreira; ambiente e condiçōes propícias ao bom trabalho pedagógico; conhecimento e domínio de processos de avaliação que reorientem as ações.

No interior da escola, outros elementos sinalizam a qualidade social da educação, entre eles, a organização do trabalho pedagógico e gestão da escola; os projetos escolares; as formas de interlocução da escola com as famílias; o ambiente saudável; a política de inclusão efetiva; o respeito às diferenças e o diálogo como premissa básica; o trabalho colaborativo e as práticas efetivas de funcionamento dos colegiados e/ou dos conselhos escolares. 
Avaliamos que a permanência e o sucesso dos estudantes dependem de outras atitudes dos profissionais da escola, como: saber reconhecer as suas potencialidades individuais; criar mecanismos facilitadores para o desenvolvimento do espírito público, responsável e colaborativo; preocupar-se com a alimentação e o transporte de estudantes, seja de carro, ônibus, barco, caminhão ou bicicletas; desenvolver a criatividade e a inovação, por meio de atividades e projetos voltados para temas atuais; possibilitar a criação artística em todas as suas manifestações (música, dança, teatro, pintura, bordados e esporte); assegurar o acesso a livros, revistas, filmes e equipamentos tecnológicos, valorizar o acesso ao cinema.

Entendemos que o bom trabalho pedagógico é aquela atividade intencional que acontece na escola, que possibilita as relações de aprendizagens entre sujeitos, orientadas pela ética profissional; é aquele que se alcança por meio de atividades voltadas para produção de ideias, de concepçôes, conceitos, valores, símbolos, hábitos, atitudes e habilidades. A educação de qualidade social implica, pois, assegurar a redistribuição da riqueza produzida e que os bens culturais sejam socialmente distribuídos entre todos.

A qualidade social da educação escolar não se ajusta, portanto, aos limites, tabelas, estatísticas e fórmulas numéricas que possam medir um resultado de processos tão complexos e subjetivos, como advogam alguns setores empresariais, que esperam da escola a mera formação de trabalhadores e de consumidores para os seus produtos. A escola de qualidade social é aquela que atenta para um conjunto de elementos e dimensões socioeconômicas e culturais que circundam o modo de viver e as expectativas das famílias e de estudantes em relação à educação; que busca compreender as políticas governamentais, os projetos sociais e ambientais em seu sentido político, voltados para o bem comum; que luta por financiamento adequado, pelo reconhecimento social e valorização dos trabalhadores em educação; que transforma todos os espaços físicos em lugar de aprendizagens significativas e de vivências efetivamente democráticas.

Recebido em novembro de 2007 e aprovado em agosto de 2008.

\section{Referências}

BANCO MUNDIAL. Prioridades y estrategias para la educación. Washington, DC: World Bank, 1996. 
CARDOSO, F.H. Mãos à obra, Brasil: proposta de governo. 5. ed. Brasília, DF, 1994.

FONSECA, M.; OLIVEIRA, J.F. A educação em tempos de mudanças: reforma do Estado e educação gerenciada. Impulso, Piracicaba, v. 16, n. 40, maio/ago. 2005.

FREITAG, B. Educação e Constituinte: implicações de uma pedagogia de qualidade. Revista Brasileira de Estudos Pedagógicos, Brasília, DF, v. 68, n. 159, maio/ago. 1987.

PEREIRA, P.A.P. Discussões conceituais sobre política social como política pública e direito de cidadania. In: Boschetti, I. et al. (Org.). Politica social no capitalismo: tendências contemporâneas. São Paulo: Cortez, 2008. p. 87-108.

SOUZA, S.Z.L.; OLIVEIRA, R.P. Políticas de avaliação da educação e quase-mercado no Brasil. Educação \& Sociedade, Campinas, v. 24, n. 84 , p. 873-895, out. 2003.

TORRES, R.M. Melhorar a qualidade da educação?: as estratégias do Banco Mundial. In: Tommasi, L.; Warde, M.J.; Haddad, S. (Org.). O Banco Mundial e as politicas educacionais. São Paulo: Cortez, 1996. p. $125-186$.

VIEIRA, E. Democracia e política social. São Paulo: Cortez; Campinas: Autores Associados, 1992. 